\title{
Patient-derived glioblastoma cells show significant heterogeneity in treatment responses to the inhibitor-of-apoptosis- protein antagonist birinapant
}

\author{
Z Zakaria $^{1,2}$, A Tivnan ${ }^{1}$, L Flanagan ${ }^{1}$, D W Murray ${ }^{1}$, M Salvucci $^{1}$, B W Stringer ${ }^{3}$, B W Day ${ }^{3}$, A W Boyd ${ }^{3}$, D Kögel $^{4}$, \\ M Rehm ${ }^{1}$, D F O'Brien², A T Byrne ${ }^{1}$ and J H M Prehn*,1 \\ ${ }^{1}$ Centre for Systems Medicine, Department of Physiology and Medical Physics, Royal College of Surgeons in Ireland, Dublin 2, \\ Ireland; ${ }^{2}$ National Centre for Neurosurgery, Beaumont Hospital, Dublin 9, Ireland; ${ }^{3}$ Brain Cancer Research Unit, QIMR Berghofer \\ Medical Research Institute, Brisbane, Queensland, Australia and ${ }^{4}$ Experimental Neurosurgery, Neuroscience Center, Frankfurt \\ University Hospital, Frankfurt am Main, Germany
}

Background: Resistance to temozolomide (TMZ) greatly limits chemotherapeutic effectiveness in glioblastoma (GBM). Here we analysed the ability of the Inhibitor-of-apoptosis-protein (IAP) antagonist birinapant to enhance treatment responses to TMZ in both commercially available and patient-derived GBM cells.

Methods: Responses to TMZ and birinapant were analysed in a panel of commercial and patient-derived GBM cell lines using colorimetric viability assays, flow cytometry, morphological analysis and protein expression profiling of pro- and antiapoptotic proteins. Responses in vivo were analysed in an orthotopic xenograft GBM model.

Results: Single-agent treatment experiments categorised GBM cells into TMZ-sensitive cells, birinapant-sensitive cells, and cells that were insensitive to either treatment. Combination treatment allowed sensitisation to therapy in only a subset of resistant GBM cells. Cell death analysis identified three principal response patterns: Type A cells that readily activated caspase- 8 and cell death in response to TMZ while addition of birinapant further sensitised the cells to TMZ-induced cell death; Type B cells that readily activated caspase-8 and cell death in response to birinapant but did not show further sensitisation with TMZ; and Type C cells that showed no significant cell death or moderately enhanced cell death in the combined treatment paradigm. Furthermore, in vivo, a Type $\mathrm{C}$ patientderived cell line that was TMZ-insensitive in vitro and showed a strong sensitivity to TMZ and TMZ plus birinapant treatments.

Conclusions: Our results demonstrate remarkable differences in responses of patient-derived GBM cells to birinapant single and combination treatments, and suggest that therapeutic responses in vivo may be greatly affected by the tumour microenvironment.

Glioblastoma multiforme or glioblastoma $(\mathrm{GBM})$ is a grade IV astrocytoma and accounts for $50-60 \%$ of all intracranial gliomas, carrying the worst prognosis of all cancers (Louis et al, 2007; Filippini et al, 2008). As per Stupp protocol, standard therapy consists of concomitant temozolomide (TMZ) and radiotherapy followed by adjuvant TMZ (Stupp et al, 2005). TMZ treatment leads to formation of the cytotoxic DNA lesion $O^{6}$-methylguanine $\left(\mathrm{O}^{6}-\mathrm{MeG}\right)$ and, ultimately, apoptosis of tumour cells (Roos et al, 2007). The evasion of apoptosis is a typical hallmark of cancer (Hanahan and Weinberg, 2000). Inhibitor-of-apoptosis-proteins (IAPs) were originally discovered in baculoviruses two decades ago due to their ability to suppress the host cell death response during

*Correspondence: Professor JHM Prehn; E-mail: JPrehn@rcsi.ie

Received 18 September 2015; accepted 10 November 2015; published online 10 December 2015

(c) 2016 Cancer Research UK. All rights reserved 0007-0920/16 
viral infection (Birnbaum et al, 1994). Cellular-IAP-1 (cIAP1), cIAP2 and X-linked-IAP (XIAP) block apoptosis by interfering with the activation of caspases in both the extrinsic and intrinsic apoptosis pathways (Fulda, 2014). The extrinsic pathway is initiated by ligands that are recognised by cell surface death receptors, such as Fas, tumour necrosis factor (TNF) or TNF-related apoptosis inducing ligand receptors (Chou et al, 2015). Upon activation, this promotes the assembly of three core proteins; receptor-interacting protein 1 (RIP1)/Fas-associated protein with death domain (FADD)/caspase- 8 that can directly cleave procaspase- 3 and -7 or activate necroptosis and other signalling pathways (Fulda, 2014). cIAP1 and cIAP2 regulate death receptor signalling mainly by means of their E3 ubiquitin ligase activity (Varfolomeev et al, 2007; Park et al, 2009). Meanwhile, the intrinsic pathway involves the activation of caspases- 3 and -7 via mitochondrial permeabilisation and the subsequent release of cytochrome $\mathrm{c}$ and Smac into the cytosol. Cytochrome $\mathrm{c}$ triggers the formation of the apoptosome, a multiprotein complex comprising of apoptotic-protease-activating-factor 1, procaspase-9, dATP/ATP and cytochrome c (Li et al, 1997; Zou et al, 1997). The apoptosome complex subsequently activates effector caspases-3 and -7 . XIAP acts in this pathway to inhibit caspase- $3,-7$ and -9 activity (Lacasse et al, 2008). Smac released during apoptosis binds XIAP and inhibits its activity (Fulda, 2014).

Many human tumours such as high-grade glioma express high levels of IAPs and aberrant expression has been linked to a defect in apoptosis, therapy resistance and poor prognosis (Lacasse et al, 2008; Vellanki et al, 2009; Murphy et al, 2013). It has been rationalised that removal of these barriers helps the diseased cells to enter apoptosis (Straub, 2011). Birinapant is a small molecule IAP antagonist currently in phase II clinical trials (www.clinicaltrials.gov) with proven efficacy in inducing apoptosis in non-CNS malignancies where the IAPs are frequently overexpressed, such as melanoma, leukaemia, breast and colorectal cancer Allensworth et al, 2013; Krepler et al, 2013; Benetatos et al, 2014). The dimeric structure of this molecule provides advantages in terms of higher binding affinities and potency to promote caspase activation, ubiquitination and proteasomal degradation of IAPs (Varfolomeev et al, 2007; Vince et al, 2007; Krepler et al, 2013; Fulda, 2014).

Little, however, is known about the efficacy of birinapant in CNS malignancy. Previous studies have demonstrated significant potential of Smac mimetics in combination with death receptor agonists in GBM cell lines (Wagner et al, 2013; Fulda, 2014). To explore the potential of birinapant as a therapeutic in GBM, we performed a comprehensive study to explore the sensitivity of a large panel of GBM cell lines to birinapant single and combination treatment with TMZ. Because response of GBM cells to birinapant treatment in vitro could differ when these cells are implanted in vivo (Eytan et al, 2015), we also investigated treatment responses in an orthotopic intracranial GBM model.

\section{MATERIALS AND METHODS}

Cell cultures. Commercially available GBM cell lines were obtained from American Type Culture Collection. Established MZ-derived GBM cell lines were obtained from Professor Donat Kögel (University Hospital, Frankfurt, Germany) (Hetschko et al, 2008). The cells were grown in complete growth medium as previously described (Murphy et al, 2013). Isolation of patient tumours for the generation of lowpassage primary patients GBMs was approved by the human ethics committee of the Queensland Institute of Medical Research and Royal Brisbane and Women's Hospital (Day et al, 2013). The cells were grown in serum-free culture medium on $1 \%$ matrigel-coated flasks, as previously described (Pollard et al, 2009). All cells were maintained in an incubator at $37^{\circ} \mathrm{C}$ in humidified air with $5 \% \mathrm{CO}_{2}$. 3-(4,5-dimethylthiazol-2-yl)-2,5-diphenyltetrazolium bromide (MTT) assay. Glioblastoma cell lines were plated in 96-well plates $\left(2 \times 10^{3}\right.$ cells per well), treated with TMZ $(150 \mu \mathrm{M})$ and/or birinapant $(1 \mu \mathrm{M})$ and a cell viability assay was carried out for the indicated time points as previously described (Murphy et al, 2013). Cell viability was determined by calculating relative changes of absorbance compared with the controls, which was set to $100 \%$ viability.

Western blotting. Glioblastoma cell lines were plated in six-well plates $\left(8 \times 10^{4}\right.$ cells per well $)$, treated with TMZ $(150 \mu \mathrm{M})$ and/or birinapant $(1 \mu \mathrm{M})$ for $96 \mathrm{~h}$. Western blotting was performed as described previously (Murphy et al, 2013) using the following antibodies at 1:1000 dilution: XIAP (Cell signalling Technology, Beverly, MA, USA), FADD (BD Biosciences, Oxford, UK), caspase-8 (ENZO Life sciences (UK) Ltd., Exeter, UK), cIAP1 (R\&D Systems, Abingdon, UK), and cIAP2 and RIP1 (Abcam, Cambridge, UK). Actin (Abcam) at 1:5000 dilution was used for loading control. Chemiluminescence signal was detected using LAS-3000 Imager equipped with a cooled 12 bit digital CCD camera (FUJIFILM UK Ltd Systems, Sheffield, UK). All western blots shown are representative of two to three independent experiments with similar results.

Flow cytometry. Glioblastoma cell lines were plated in 24-well plates $\left(1 \times 10^{4}\right.$ cells per well), pretreated with of $\mathrm{zVAD}(50 \mu \mathrm{M})$ for $60 \mathrm{~min}$ and then treated with $\mathrm{TMZ}(150 \mu \mathrm{M})$ and/or birinapant $(1 \mu \mathrm{M})$ for $96 \mathrm{~h}$. Following treatment, monolayer cells were harvested with trypsin-EDTA or accutase, and were then incubated in binding buffer (10 mM HEPES, $135 \mathrm{~mm} \mathrm{NaCl}, 5 \mathrm{mM} \mathrm{CaCl}_{2}$ ), containing $1 \mu \mathrm{lml}^{-1}$ of annexin V-FITC conjugate and/or $1 \mu \mathrm{g} \mathrm{ml}^{-1}$ of propidium iodide (PI) (Bio Vision, Mountain View, CA, USA) for 15 min on ice. Cells were counted in a Partec Cyflow ML16 flow cytometer (Partec, Münster, Germany). Annexin V-FITC was excited with the $488 \mathrm{~nm}$ laser, and fluorescence emission was collected in the FL1 channel through a $520 \mathrm{~nm}$ band pass filter. PI was excited with the $488 \mathrm{~nm}$ laser, and fluorescence emission was collected in the FL2 or FL3 channel through $575-605 \mathrm{~nm}$ or $630 \mathrm{~nm}$ band pass filter, respectively. Compensation for crosstalk was performed as required. In total, $1 \times 10^{4}$ gated cells were required for each sample.

Hoechst staining and phase contrast microscopy. GBM cell lines were plated in 24 -well plates $\left(1 \times 10^{4}\right.$ cells per well $)$ and treated with TMZ $(150 \mu \mathrm{M})$ and/or birinapant $(1 \mu \mathrm{M})$ for $96 \mathrm{~h}$. Hoechst and phase contrast images was performed as described previously (Murphy et al, 2013). Using Image J software (NIH, USA), those cells with condensed/fragmented nuclei were deemed apoptotic, counted and expressed as a percentage of the apoptotic cells per treatment group.

In vivo orthotopic xenograft GBM studies. All animal experiments were licensed by the Department of Health and Children, Dublin, Ireland. Protocols were reviewed by the Royal College of Surgeons in Ireland Research Ethics Committee. Forty female NOD/SCID mice (5-6 week) were purchased from Charles River Laboratories (Canterbury, UK) and maintained in isolated facility within a specific pathogen-free environment. RN1luc cells $\left(5 \times 10^{5}\right)$ stably expressing luciferase were selected for xenograft studies. The experimental techniques for orthotopic implantation and bioluminescence imaging (BLI) were performed as previously described (Jarzabek et al, 2013). Once the tumour reached exponential growth phase, animals were randomised into four groups: vehicle, TMZ, birinapant and TMZ plus birinapant $(n=10$ mice per cohort). TMZ ( $25 \mathrm{mg} \mathrm{kg}^{-1}$ formulated in $10 \%$ DMSO in sterile $\mathrm{PBS} \times 7$ days) was delivered via oral gavage. Animals received birinapant via an intraperitoneal injection (i.p.) (20 $\mathrm{mg} \mathrm{kg}^{-1}$ every 3 days (nine doses in total)). The combination group received both drugs. Animals were killed when moribund. 
Statistics. Detail of statistical analysis is available in Supplementary data.

\section{RESULTS}

GBM cells show a heterogeneous sensitivity to TMZ and birinapant single treatment with enhanced sensitisation achieved with combined treatment. Reflecting the heterogeneity of GBM cells, we used a panel of 15 GBM cell lines, which consisted of five commercially available GBM cell lines (U87, U251, A172, U343 and U373), a cohort of cell lines derived from patient GBMs including four primary (MZ294, MZ327, MZ51 and MZ18) and two recurrent tumours (MZ304 and MZ256) (Hetschko et al, 2008), and four cell lines from low-passage primary patient GBMs (JK2luc, WK1luc, RN1luc and SJH1luc) (Day et al, 2013; Tivnan et al, 2014). The cells were incubated with $\mathrm{TMZ}$ at $150 \mu \mathrm{M}$ (Murphy et al, 2013), and/or birinapant at $1 \mu \mathrm{M}$, a concentration that has been proven to be pharmacodynamically active in cancer cell lines (Allensworth et al, 2013; Krepler et al, 2013). Cell viability was analysed at five different time points using the MTT assay.

Following analysis of cell line responses, three distinct response patterns were observed; TMZ-sensitive cells, birinapant-sensitive cells, as well as cells that were insensitive to either treatment (Figure 1). During the first $48 \mathrm{~h}$ of incubation, TMZ and birinapant single treatments were not effective in inducing cell death, with cell viability remaining above $\sim 80 \%$. Sensitive cells responded to TMZ treatment earlier than birinapant, with two of the commercially available cell lines (A172 and U251) showing TMZ sensitivity at $72 \mathrm{~h}$ post treatment onset $(P<0.05)$. All commercially available GBM cell lines showed persistent reduction in cell survival at $96 \mathrm{~h}$ of treatment (Figure 1A). The cells that were insensitive to either treatment showed no significant effect on cell survival despite the prolonged incubation periods (Figure 1B, C, E and F). In contrast, birinapant-sensitive cell lines comprised of a mixture of the commercial and patient-derived GBMs, with a moderate reduction in cell viability evident at $96 \mathrm{~h}$ in 4 (A172, U251, U87 and JK2luc), and at $120 \mathrm{~h}$ in 7 of the 15 cell lines investigated (Figure 1D).

Following combination treatments of TMZ plus birinapant, the cells were further categorised into four distinct response patterns. During the first $48 \mathrm{~h}$ of incubation, two cell lines (A172 and U251) that were sensitive to both TMZ and birinapant single treatments were below $80 \%$ survival in the combined regimen (Figure 1G; $P<0.05$ ), with further reductions observed at $72 \mathrm{~h}$ of treatment. A similar effect was observed in TMZ-sensitive U373 cells where a significant reduction of cell survival was evident at $72 \mathrm{~h}$ of treatment, and in two birinapant-sensitive cell lines (RN1luc and JK2luc) at $96 \mathrm{~h}$ (Figure $1 \mathrm{H} ; P<0.05$ ). Two cell lines (WK1luc and MZ18) that were resistant to both single treatments were sensitised after $96 \mathrm{~h}$ of treatment, with a further (MZ327) at $120 \mathrm{~h}$ (Figure 1I; $P<0.05$ ). Nevertheless, four GBM cells (MZ294, SJH1luc, MZ51 and MZ256) remained resistant even to a combined treatment over $120 \mathrm{~h}$ (Figure 1J). Together, this set of experiments demonstrated that birinapant treatment differentially sensitised GBM cells to TMZ, with a subset of cell lines permitting an additional
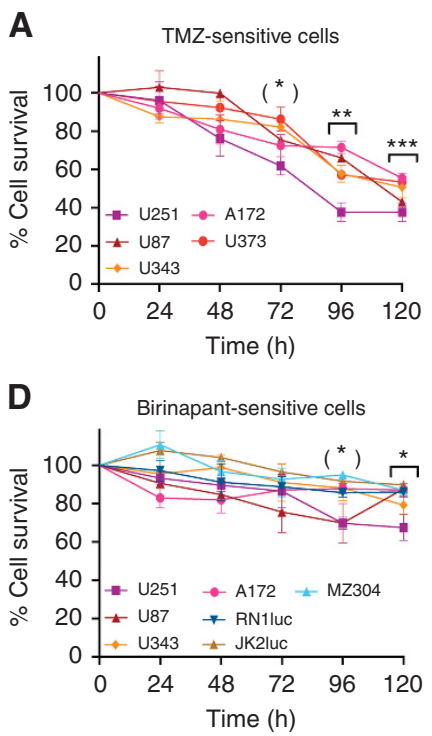
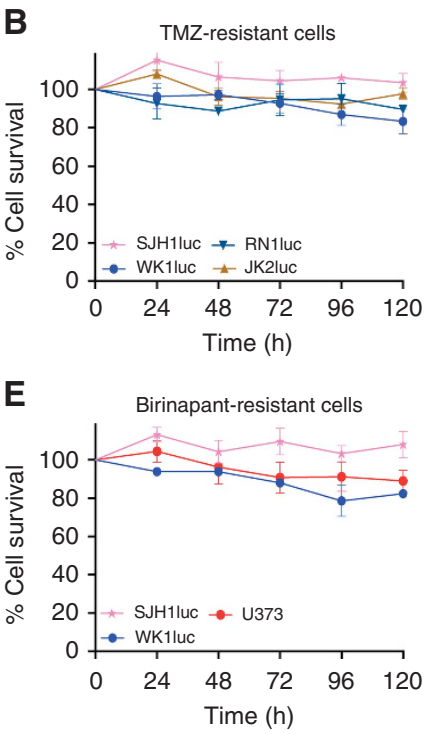
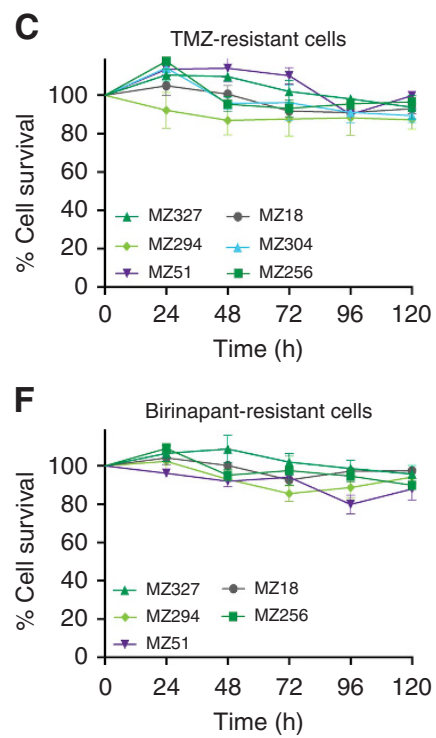
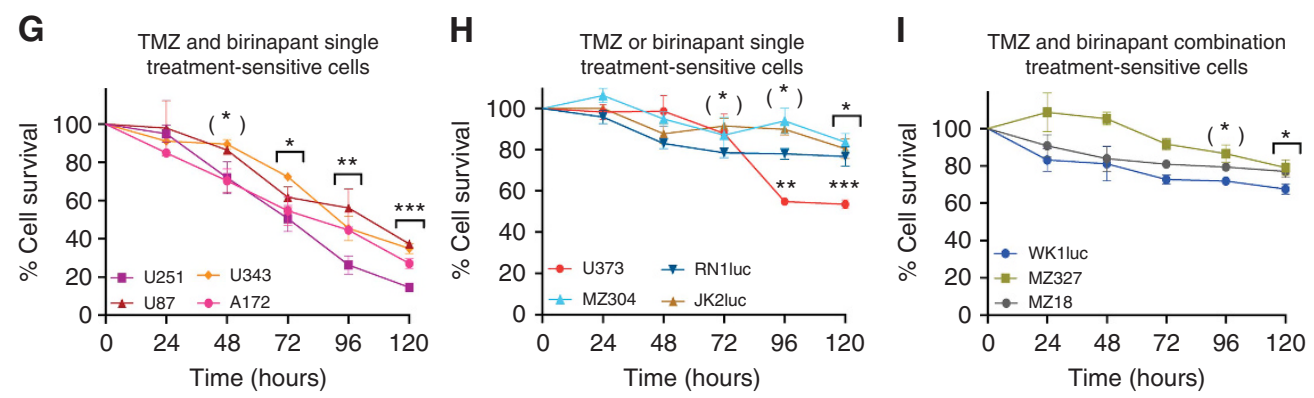

J

$\mathrm{TMZ}$ and birinapant-resistant cells

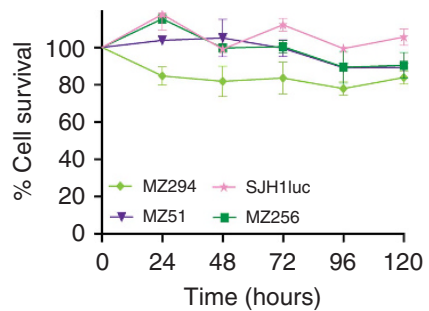

Figure 1. Effect of single and combination treatments on cell survival in a panel of GBM cells. (A-C) The characteristics of TMZ-sensitive cells were observed at $72 \mathrm{~h}$ post treatment, (D-F) whereas birinapant-sensitive cells at $96 \mathrm{~h}$ post treatment. (G) For combination treatments, additional reduction in cell survival were evident at $48 \mathrm{~h}$ post treatment in cells that were sensitive to TMZ and birinapant single treatment, $(\mathrm{H})$ and at $72 \mathrm{~h}$ post treatment in TMZ- or birinapant-sensitive cells. (I) Three of the GBM cells that were resistant to single treatments had benefited from combined treatments. (J) Four of the GBM cells remained resistant to the treatments. One-way ANOVA, ${ }^{\star} P<0.05,{ }^{\star \star} P<0.01,{ }^{\star \star \star} P<0.001$. 
sensitisation of cells that were resistant to single treatments. For subsequent experiments, two GBM cells from each groups were selected; U87 and U251 (commercially available GBM cells), MZ294 and MZ304 (primary and recurrent MZ-derived patient GBMs) and RN1luc and WK1luc (low-passage luciferase positive primary patient GBMs).

Evaluation of IAP proteins levels in GBM cells treated with TMZ and birinapant. To validate that birinapant targeted IAPs in the selected cell lines, western blot analysis of cIAP1, cIAP2 and XIAP protein levels was conducted (Figure 2). Following $96 \mathrm{~h}$ of treatment, birinapant as a single agent as expected caused the degradation of cIAP1, as the protein is auto-ubiquitinated and degraded via the proteasome in response to IAP antagonist treatment (Fulda, 2014). We observed degradation of cIAP1 in all selected GBM cells, with U251 cells showing complete degradation only in response to the TMZ plus birinapant or TMZ single treatment. There was little evidence for significant changes in cIAP2 and XIAP protein levels in line with the fact that autoubiquitination, and proteasomal degradation is a feature of cIAP1 but not cIAP2 and XIAP (Vince et al, 2007; Condon et al, 2014). Exceptions to this were U251 cells where the exposure to TMZ alone and in combination with birinapant induced degradation of CIAP2 and XIAP, and MZ304 where the exposure to birinapant alone or in combination with TMZ induced degradation of XIAP.

Cell death analysis after TMZ and birinapant single and combined treatments identifies three principal cell death response patterns. In order to further elucidate this apparent heterogeneity in treatment responses, we performed a more detailed analysis of cell death pathways activated or not in response to TMZ and birinapant. Flow cytometry analysis of PI uptake and annexin V-FITC staining was conducted following $96 \mathrm{~h}$ of treatment with single or combination therapies, both in the presence and absence of the caspase inhibitor, zVAD. Cells positive for annexin $\mathrm{V}$ binding (as a marker for apoptosis activation) and PI-positive cells (cells that underwent membrane rupture after 'primary' of 'secondary necrosis') were quantified (Henry et al, 2013). To further characterise the morphology of GBM cells, the condensation and fragmentation of nuclei was assessed using Hoechst staining.

In agreement with the MTT assay data, cell death analysis in response to single and combined treatments identified three major principal response patterns. The first response pattern ('Type A' cell) was seen in TMZ-sensitive U251 cells. Flow cytometry analysis showed significant apoptotic and 'secondary necrotic' cell death in response to TMZ but not birinapant, which was sensitive to zVAD treatment (Figure 3A-D). Similar response patterns were identified in U87 cells (Supplementary Figure 1). Combined treatment with birinapant further enhanced cell death, a finding also confirmed by morphological analysis of nuclear condensation (Figure $3 \mathrm{E}$ and F). Western blot analysis after $96 \mathrm{~h}$ of treatment demonstrated processing of procaspase- 8 into p41 and p18 subunits, indicative of caspase- 8 activation. This was accompanied by an increase in FADD protein levels and a decrease in RIP1 protein levels (Figure 3G).

A second principal response pattern ('Type B' cell) was seen in the birinapant-sensitive WK1luc cells. Flow cytometry analysis revealed increases in PI uptake in response to birinapant or birinapant plus TMZ, but not to TMZ alone (Figure 4A-D). Cell death was completely inhibited by the caspase inhibitor zVAD. Cell death activation was confirmed by a quantitative analysis of cell death using Hoechst staining (Figure 4E and F). Western blot analysis indicated that birinapant treatment readily activated caspase-8, and led to an increase in FADD and reduction in RIP1 protein levels (Figure 4G).

A third response pattern ('Type C' cell) was seen in RN1luc, MZ294 and MZ304 cells that showed moderate (RN1luc and MZ304) or no response (MZ294) to birinapant or birinapant plus TMZ treatments in the previous MTT assays. Flow cytometry analysis revealed that RN1luc cells showed moderate sensitisation to cell death with the combined treatment. This reached the level of statistical significance in the flow cytometry and Hoechst staining experiments. This sensitisation was sensitive to $\mathrm{zVAD}$ treatment (Figure 5A-F). Western blot analysis of RN1luc cells demonstrated no detectable caspase- 8 activation and a loss of RIP1 protein levels following birinapant treatment (Figure 5G). MZ294 and MZ304 showed no effects of the combined treatments on cell death as measured by PI uptake (Supplementary Figure S2). MZ294 and MZ304 cells showed moderate annexin V-FITC staining and nuclear condensation in response to TMZ plus birinapant by flow cytometry analysis and Hoechst staining that was sensitive to $\mathrm{zVAD}$.

In vivo analysis of 'Type C' RN1luc cells in an intracranial xenograft model. Type C RN1luc cells that stably expressing luciferase was next selected to determine whether sensitisation could be achieved in vivo, following orthotopic intracranial tumour cell delivery. Treatment commenced 63 days following tumour cell inoculation. Figure $6 \mathrm{~A}$ presents study time points for drug combination treatment with weekly BLI performed. Birinapant treatment had no impact on tumour growth as reflected by an increasing bioluminescent signal similar to the vehicle group $(P=0.2420)$. In contrast, TMZ and TMZ + birinapant significantly inhibited tumour growth $(P<0.0001$ for both). TMZ + birinapant treatment did not have a significantly greater tumour growth inhibitory effect when compared with TMZ after adjustment for multiple testing $(P=0.9116)$, however, a significant effect was observed when TMZ and TMZ + birinapant were compared with birinapant $(P<0.0001$ for both). Nevertheless, after 49 days post treatment, tumour growth inhibition was greatest in the TMZ+ birinapant group (Figure 6B). Bioluminescent images of representative mice from experimental cohort at 35 or 84 days post treatment commencement are shown in Figure 6C.

Survival analysis revealed that $\mathrm{TMZ}$ and $\mathrm{TMZ}+$ birinapant elicited a significant survival benefit, with median survival of 161.5 days and 173.5 days, respectively, compared with vehicle (92.5 days; $P<0.0001$ for both) (Figure 6D). Comparing

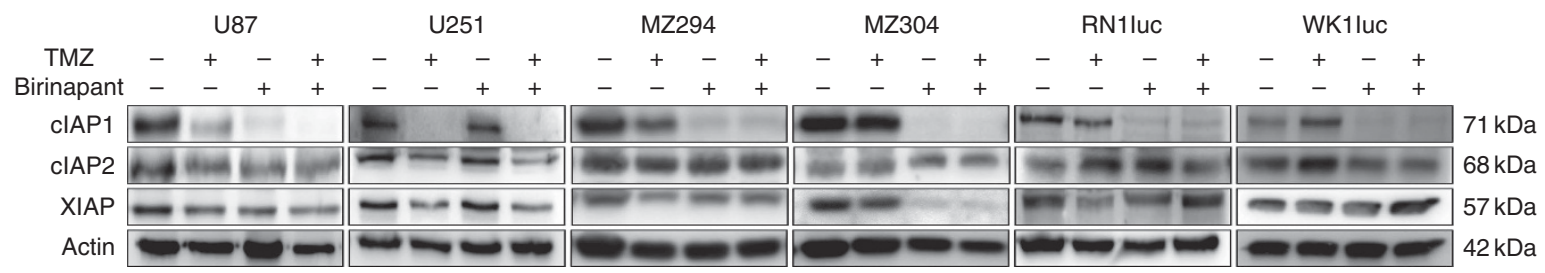

Figure 2. Effects of single and combination treatments on IAPs expression profiling. Birinapant as a single agent causes the degradation of clAP1 in all selected GBM cells, with U251 cells showing complete degradation only in response to the TMZ single and combination treatments. Exposure to TMZ and TMZ plus birinapant induced degradation of XIAP in U251 cells, whereas exposure to birinapant and birinapant plus TMZ did the same in MZ304 cells. Actin was used as a loading control. 

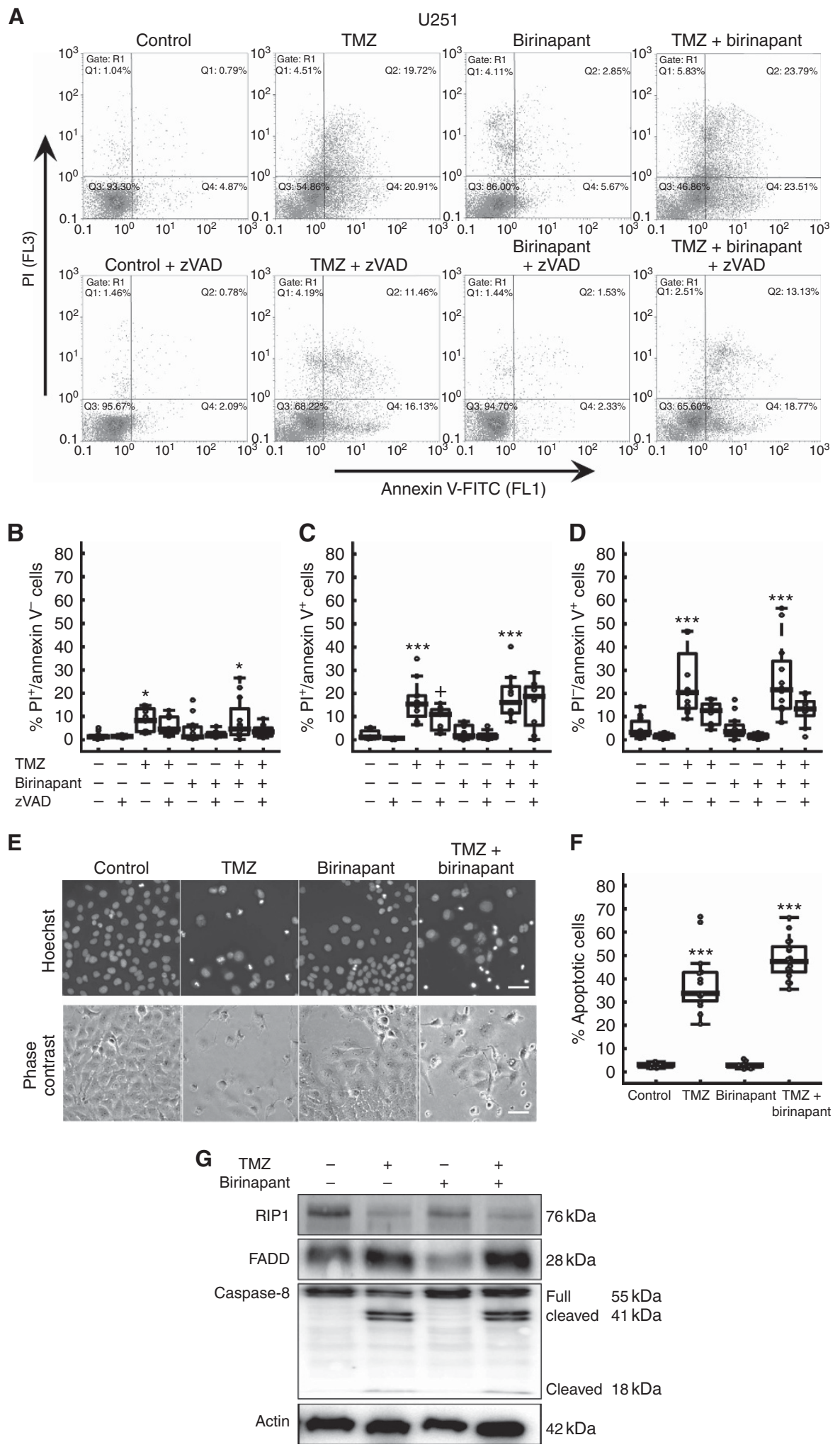

Figure 3. Type A response pattern in TMZ-sensitive U251 cells. (A-D) Flow cytometry analysis identified a significant apoptotic and secondary necrotic cell death in response to TMZ but not birinapant, with partial sensitivity to zVAD treatment. (E, F) Combined treatment with birinapant further enhanced cell death, a finding also confirmed by morphological analysis of nuclear condensation. Two-way ANOVA, ${ }^{*} P<0.05,{ }^{\star \star} P<0.01$, ${ }^{* \star *} P<0.001$ versus control cells. Scale bar, $50 \mu \mathrm{m}$. (G) Protein expressions show that the TMZ alone and in combination accelerate caspase-8 cleavage and induced reduction of RIP1 and further increased of FADD expression. Actin was used as a loading control.

median survival between animals in birinapant and vehicle cohorts, we found no significant difference $(P=0.042)$ after adjustment for multiple testing, suggesting that the survival benefit was due to tumour sensitisation with TMZ.
Although the addition of birinapant to TMZ treatment elicited a modest median survival advantage of 12 days $(P=0.0293)$ compared with TMZ animals, this was not statistically significant. 
A

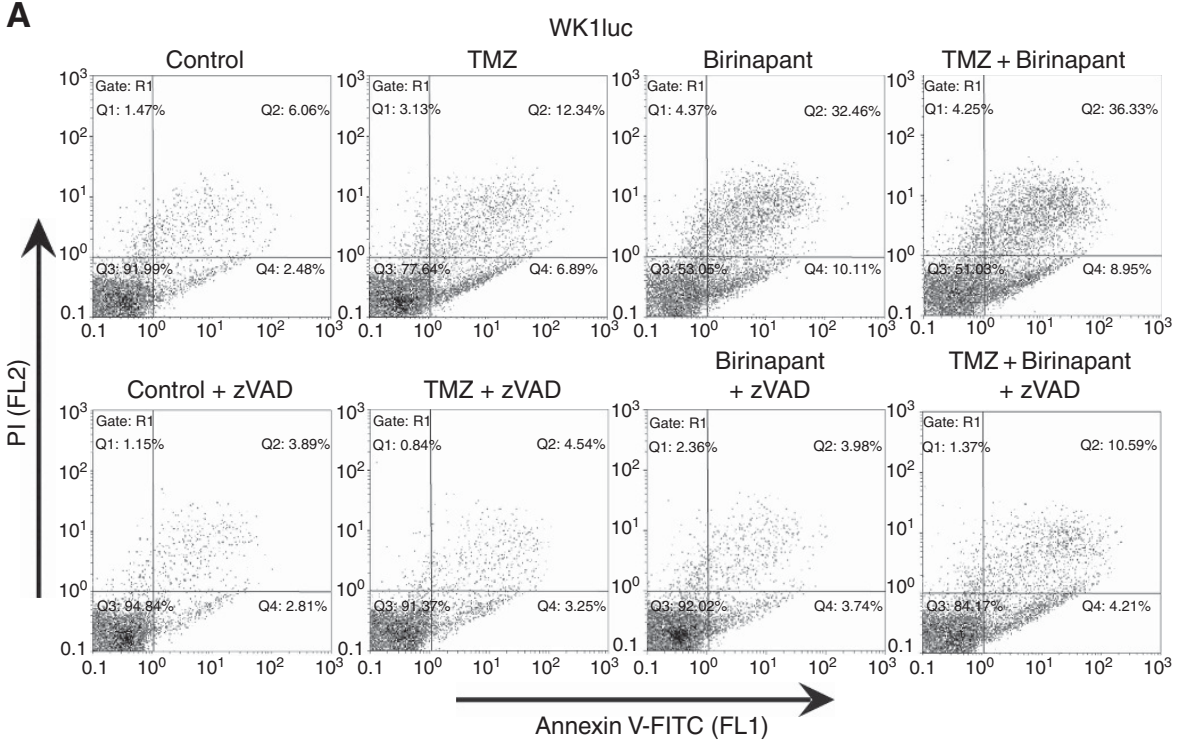

B

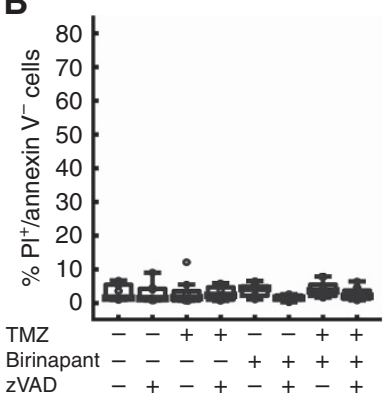

$\mathbf{E}$
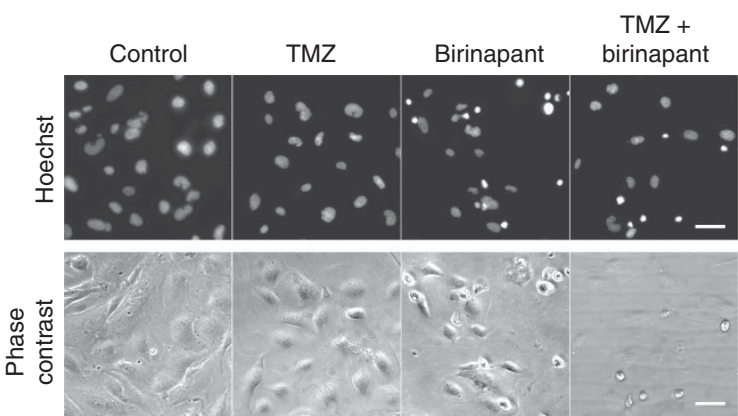

G
C

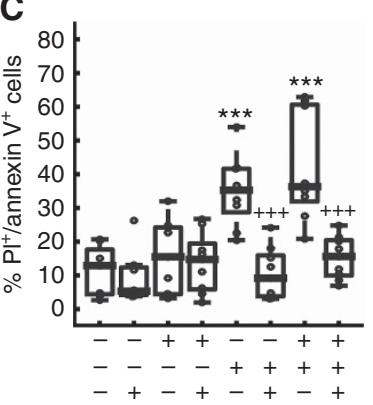

D

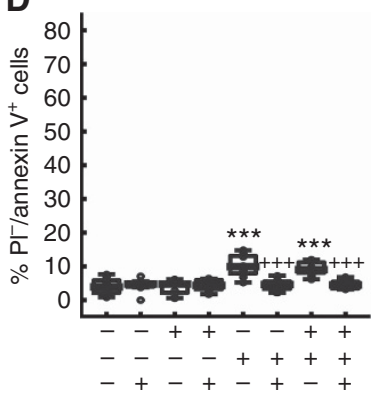

$\mathbf{F}$
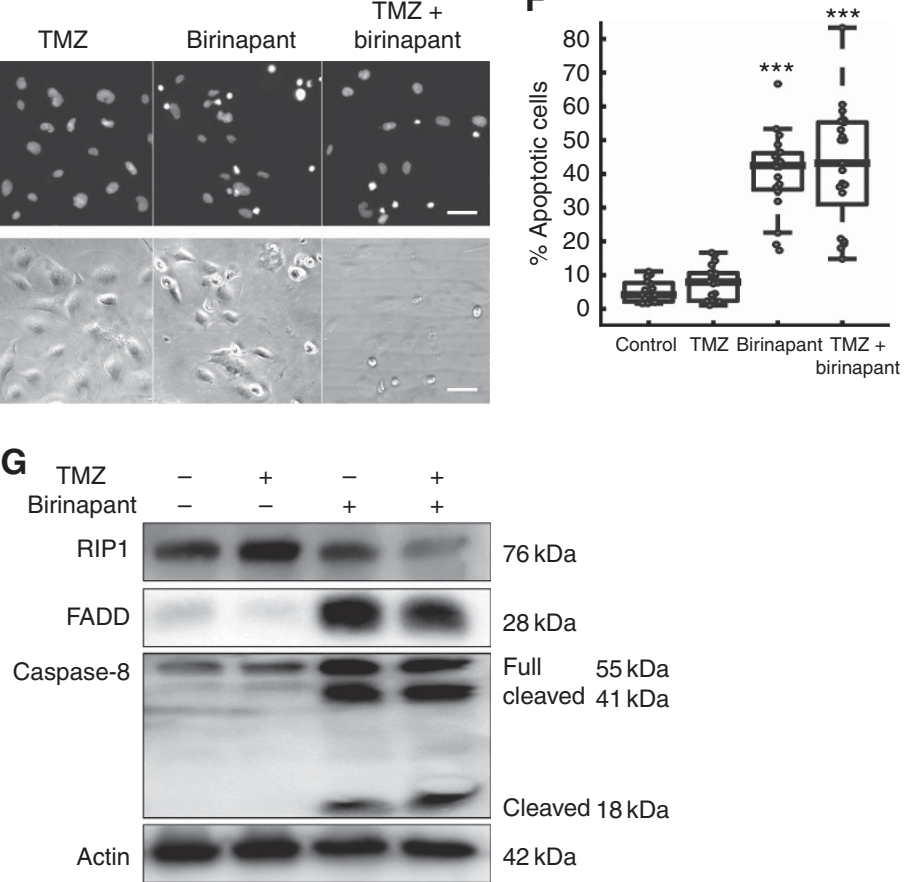

Figure 4. Type B response pattern in birinapant-sensitive WK1luc cells. (A-D) Flow cytometry analysis demonstrated that birinapant and birinapant plus TMZ induced significant zVAD-sensitive ('secondary necrotic') cell death. (E, F) A similar finding was observed by Hoechst staining; data are shown as a boxplot with overlaid data points from at least three independent experiments with technical replicates (two-way ANOVA, ${ }^{* * *} P<0.001$ versus control cells, ${ }^{+}++P<0.001$ versus treated cells. Scale bar, $50 \mu \mathrm{m}$. (G) Western blot analysis indicated that birinapant treatment readily activated caspase-8, and lead to an increase in FADD and reduction in RIP1 protein levels. Actin was used as a loading control. 

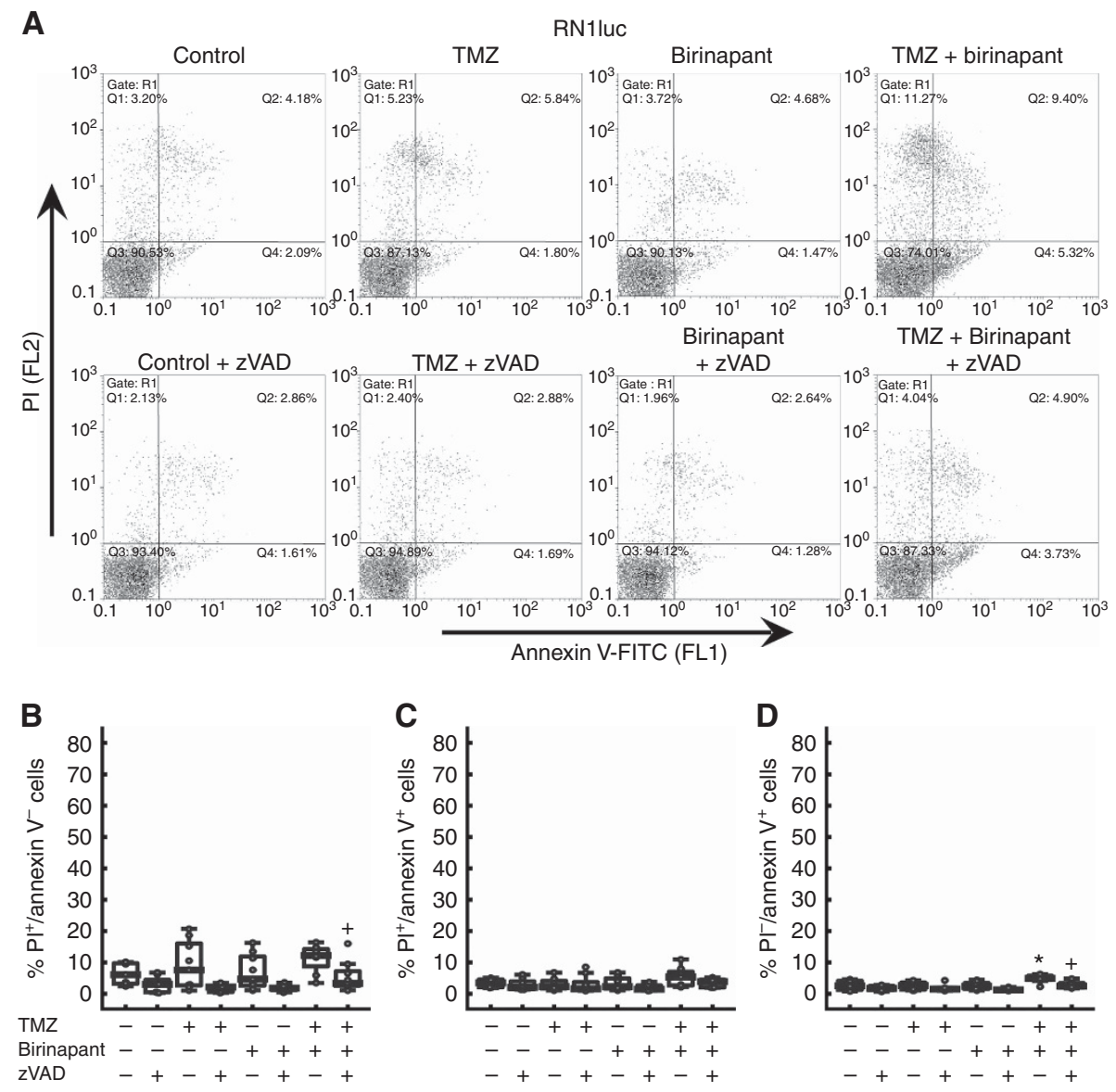

E
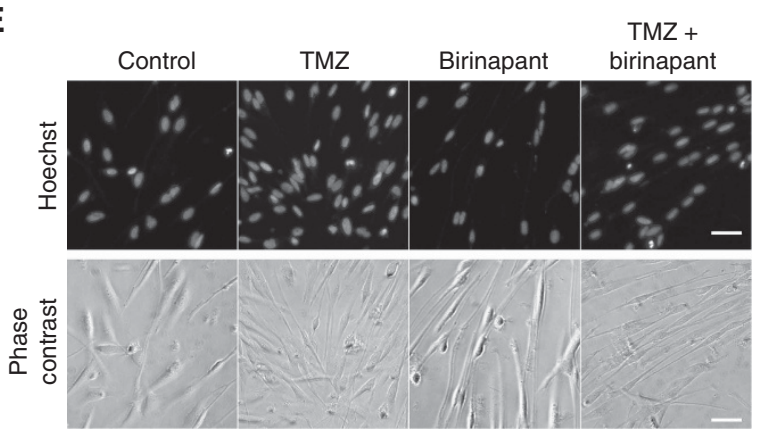

$\mathbf{F}$
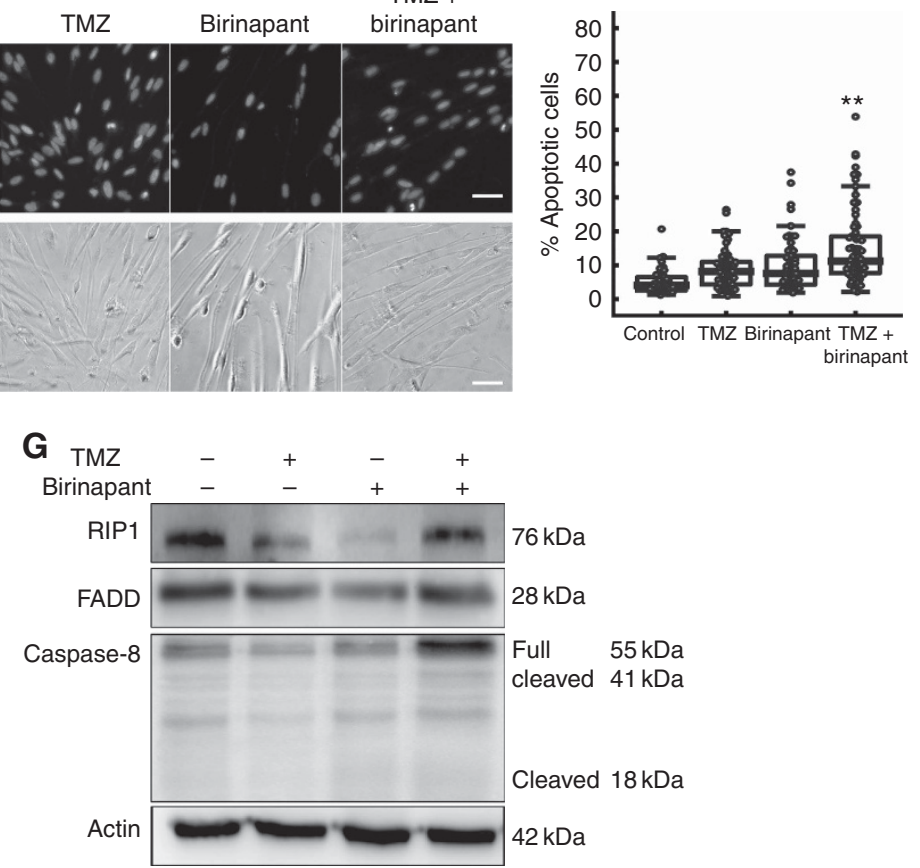

Figure 5. Type $\mathrm{C}$ response pattern in RN1luc cells. (A-D) Flow cytometry analysis showed moderate sensitisation with the combined treatment. Cell death was not entirely blocked by zVAD. (E, F) A similar finding was observed by Hoechst staining. Two-way ANOVA, * $P<0.05$ versus control cells, ${ }^{+} P<0.05$ versus treated cells. Scale bar, $50 \mu \mathrm{m}$. (G) Western blot analysis demonstrated a loss of RIP1 expression following birinapant treatment but addition of TMZ reversed the effect of birinapant. Neither single nor combination treatment induced any loss of FADD expression nor cleavage of caspase-8. Actin was used as a loading control. 
A

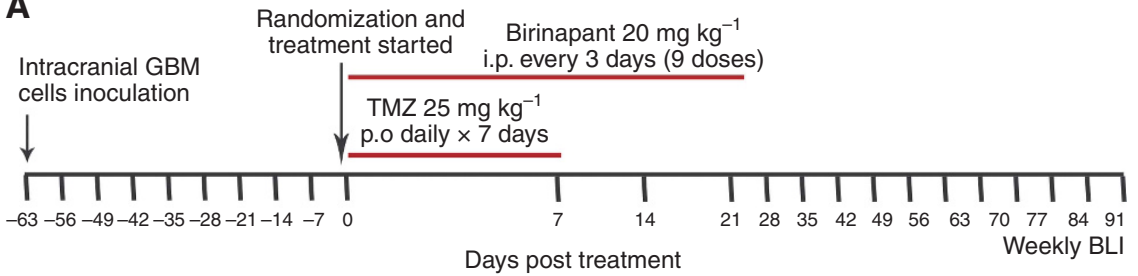

B

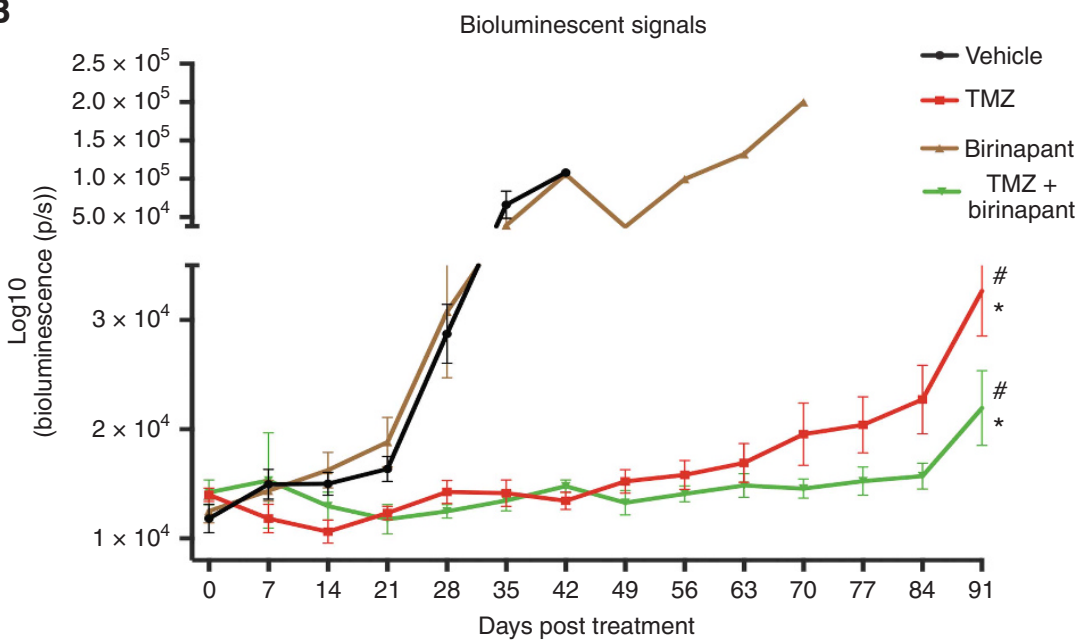

C
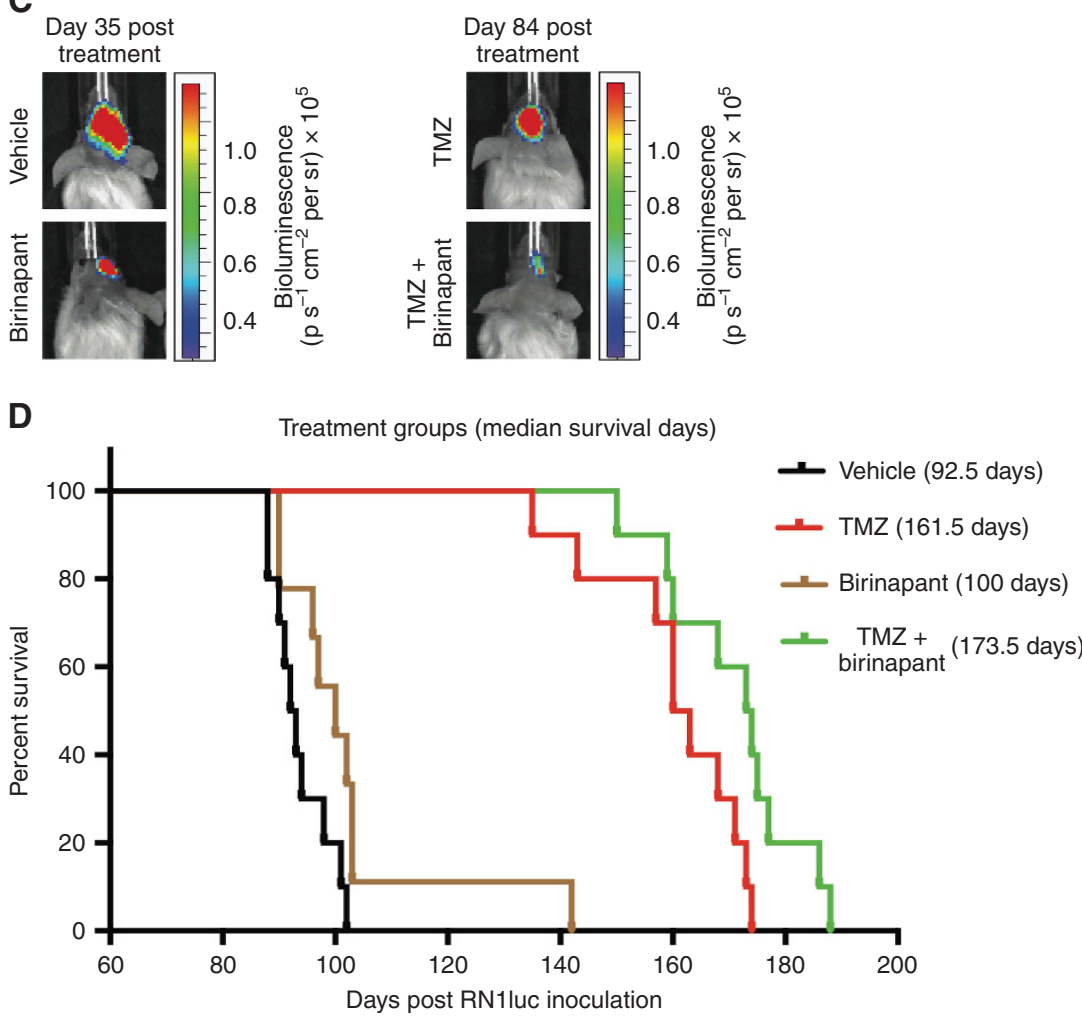

Figure 6. In vivo tumour growth (bioluminescence) and survival analysis for intracranially inoculated luciferase-expressing RN1luc orthoxenografts. (A) Drug combination treatment and weekly BLI are presented. (B) Effect of TMZ, birinapant or combination on tumour growth. (C) Images show tumour growth over time in a representative animal from each treatment group at 35 days post treatment commencement. (D) Effect of treatment on survival using Kaplan-Meier analysis and log-rank tests was used to compare treatment groups. Error bars represent mean BLI \pm s.e.m ( $n=10$ animals per group). ${ }^{\star} P<0.0001$ versus vehicle and ${ }^{\#} P<0.0001$ versus birinapant; statistically significant using a Bonferroni-adjusted significance level of $0.83 \%(P<0.0083)$. 


\section{DISCUSSION}

The development of IAP antagonists as potential anticancer agents has gained significant interest as inhibition of IAPs has been shown to sensitise various cancer cells to pro-apoptotic agents (Varfolomeev et al, 2007; Fulda, 2014). Our result show surprisingly heterogeneous responses in commercial and patientderived GBM cells treated with birinapant in vitro, either as a single agent or when combined with TMZ. Heterogeneous responses to Smac mimetics have been reported in non-smallcell lung cancer cells and A172 cells (Petersen et al, 2010; Wagner et al, 2013), whereas other reports described more homogeneous effects in acute myeloid leukaemia, and breast cancer cells (Benetatos et al, 2014; Carter et al, 2014). Responses to TMZ, birinapant and the combination of TMZ plus birinapant could be classified into three principal response patterns: Type A cells showing cell death in response to TMZ, with addition of birinapant showing further sensitisation to TMZ induced cell death; Type B cells showing responses to birinapant but no further sensitisation with TMZ; and Type C cells showing no significant cell death or moderately enhanced cell death in the combined treatment paradigm. Furthermore, we show that responses to patient-derived GBM cells in vivo may increase significantly when compared with responses in vitro, suggesting that the tumour microenvironment has an important role in treatment responses.

We noted that all commercially available GBM cell lines were TMZ-sensitive and all patient-derived GBM cell lines were TMZ-resistant. In contrast, 'responders' to birinapant were observed in both groups, albeit the magnitude of responses to single-agent birinapant treatment was significantly smaller in both commercial and patient-derived GBM cells. This finding highlights the importance of the inclusion of patient-derived GBM cells in preclinical in vitro and in vivo studies. In addition, MGMT status alone has not been found to correlate to the TMZ responsiveness in vivo in the patient-derived cell lines assessed in this study (Murphy et al, 2013).

The Type A cells (such as U251 cells) were sensitive to TMZ and showed further sensitisation when the treatment was combined with birinapant. The mode of cell death was mainly apoptotic or 'secondary' necrotic, as identified by annexin V and PI uptake and protection with the caspase inhibitor zVAD. Activation of apoptosis is consistent with the DNA damage response induced by TMZ (Roos and Kaina, 2013), which triggers caspase activation (Roos et al, 2007). Sensitisation of GBM cells towards TMZinduced apoptosis by birinapant or other Smac mimetic has previously been demonstrated to involve caspase- 8 activation as a key mechanism (Wagner et al, 2013). We also noted that RIP1 protein levels were low in response to TMZ and TMZ plus birinapant, likely a consequence of caspase- 8 activation (Lin et al, 1999). Interestingly, absence or low expression of cleaved caspase- 8 and overexpression of RIP1 have been shown to serve as independent negative prognostic indicators in GBM (Park et al, 2009; Saggioro et al, 2014).

The Type B cells (such as WK1luc cells) were sensitive to singleagent birinapant treatment, but no further sensitisation with TMZ was observed. Birinapant or birinapant plus TMZ treatment induced 'secondary' necrotic cell death that was zVAD-sensitive (annexin V and PI-positive cells). We also observed annexin V-positive and PI-negative cells. This cell death was, however, also zVAD-sensitive, and Hoechst staining indicated strong nuclear condensation, indicating that these cells did not undergo a primary necrotic cell death. The appearance of such double-positive cells is likely a consequence of ruptured membranes late during apoptosis that sheared off apoptotic nuclei during flow cytometric sample reading. Cell death in response to birinapant was associated with a strong FADD and procaspase- 8 upregulation, suggesting that birinapant treatment enabled the formation of caspase- 8 activating platforms such as the ripoptosome (Varfolomeev et al, 2007; Bai et al, 2014). Western blot experiments also demonstrated caspase- 8 activation and reduced RIP1 protein levels. Cleavage of RIP1 by caspase-8 has previously been reported (Lin et al, 1999).

The Type C cells (such as RN1luc, MZ294 and MZ304 cells) however were largely resistant to either single treatment and only capable of activating moderate cell death when the treatments were combined. In MZ294 cells, we noted significant annexin V binding, which was blocked by zVAD, yet only a small fraction of cells eventually underwent cell death. A 'sublethal' apoptosis activation was confirmed in our western blot analysis, where the treatments failed to activate caspase- 8 and where FADD expression remained stable. Activation of caspase- 8 , therefore, may represent a better predictor of birinapant and TMZ responsiveness in GBM cells than annexin $\mathrm{V}$ binding. Western blot analysis showed downregulation of cIAP1 protein in all GBM cell lines tested. It can therefore be concluded that the downregulation of cIAP1 protein levels were not sufficient to activate caspase- 8 and promote cell death in type $\mathrm{C}$ cells. This has previously not been noted in other cellular models (Tenev et al, 2011; Wagner et al, 2013).

Although many ongoing (pre)clinical trials for birinapant, either alone or in combinations with other chemotherapy agents were conducted on non-CNS cancer, we elucidated the role of birinapant as a targeted therapy for GBM in an orthotopic model. From the observed Type C RN1luc cells response pattern in vitro, the therapeutic potential of birinapant in vivo were predicted to be limited, even with the combined treatment. The RN1luc cells, to our surprise, exhibited sensitivity and antitumour activity to $\mathrm{TMZ}$ and $\mathrm{TMZ}$ plus birinapant treatment in vivo. RN1luc cells are MGMT unmethylated (Tivnan et al, 2014), and yet in vivo treatment showed a surprising sensitivity to TMZ. It has been shown that GBM cells with unmethylated MGMT promoter remain resistant to TMZ treatment after a single and repeated in vitro exposure, but become highly sensitive when treated in vivo (Kitange et al, 2009). In addition, culturing cells via monolayer (2D, adherent) could limit the efficacy of chemotherapeutics agents. Even with the improved monolayer technique as applied in this study (described by Pollard et al, 2009), the methylation and transcription profiles between in vitro and in vivo models have been shown to be different (Baysan et al, 2014). Important signals and key regulators needed for drug uptake into the cells or drug action could occur naturally within in vivo microenvironment. Although literature is still lacking in studies of relevance of TMZ treatment on tumour stroma cells (Jones and Holland, 2012), it is possible that the stroma cells are also important for drug actions in vivo.

The effects of birinapant single-agent treatments in vivo were less pronounced, as predicted from our in vitro studies. We cannot fully exclude that birinapant has limited blood-brain barrier permeability, preventing the molecule to reach its target. However, a role for TMZ in increasing the permeability of the blood-brain barrier to allow co-treated drugs to reach the tumour cells has been reported (Riganti et al, 2014). This could explain the tendency towards an increased survival advantage in the TMZ plus birinapant group.

In conclusion, our data demonstrate that GBM cells show heterogeneous treatment responses in vitro to birinapant alone or in combination with TMZ, and can be principally subgrouped into three different response patterns. Furthermore, we demonstrate that tumour microenvironment affects GBM cells sensitivity to TMZ and combined TMZ and birinapant treatment. Our findings also give an insight into the challenges of identifying new treatments for GBM, and highlight the importance of intracranial GBM models in such studies. 


\section{ACKNOWLEDGEMENTS}

Funding is acknowledged from Science Foundation Ireland (13/IA/ 1881 and 14/IA/2582) and the European Union's Seventh Framework Programme for research, technological development, and demonstration under grant agreement 306021 (APO-DECIDE) to JHMP and MR. ATB is funded under the European Union's Seventh Framework Programme under grant agreement 278981 (AngioPredict). AT is funded by the Irish Cancer Society (CRF13TIV) and supported by Tesco Charity of the Year.

\section{CONFLICT OF INTEREST}

The authors declare no conflict of interest.

\section{REFERENCES}

Allensworth JL, Sauer SI, Lyerly HK, Morse MA, Devi GR (2013) Smac mimetic birinapant induces apoptosis and enhances TRAIL potency in inflammatory breast cancer cells in an IAP-dependent and TNF-alphaindependent mechanism. Breast Cancer Res Treat 137: 359-371.

Bai L, Smith DC, Wang S (2014) Small-molecule SMAC mimetics as new cancer therapeutics. Pharmacol Ther 144: 82-95.

Baysan M, Woolard K, Bozdag S, Riddick G, Kotliarova S, Cam MC, Belova GI, Ahn S, Zhang W, Song H, Walling J, Stevenson H, Meltzer P, Fine HA (2014) Micro-environment causes reversible changes in DNA methylation and mRNA expression profiles in patient-derived glioma stem cells. PLoS One 9: e94045.

Benetatos CA, Mitsuuchi Y, Burns JM, Neiman EM, Condon SM, Yu G, Seipel ME, Kapoor GS, Laporte MG, Rippin SR, Deng Y, Hendi MS, Tirunahari PK, Lee YH, Haimowitz T, Alexander MD, Graham MA, Weng D, Shi Y, McKinlay MA, Chunduru SK (2014) birinapant (TL32711), a bivalent SMAC mimetic, targets TRAF2-associated cIAPs, abrogates TNF-induced NF-kappaB activation, and is active in patientderived xenograft models. Mol Cancer Ther 13: 867-879.

Birnbaum MJ, Clem RJ, Miller LK (1994) An apoptosis-inhibiting gene from a nuclear polyhedrosis virus encoding a polypeptide with Cys/His sequence motifs. J Virol 68: 2521-2528.

Carter BZ, Mak PY, Mak DH, Shi Y, Qiu Y, Bogenberger JM, Mu H, Tibes R, Yao H, Coombes KR, Jacamo RO, McQueen T, Kornblau SM, Andreeff M (2014) Synergistic targeting of AML stem/progenitor cells with IAP antagonist birinapant and demethylating agents. J Natl Cancer Inst 106: djt440.

Chou YC, Chang MY, Wang MJ, Harnod T, Hung CH, Lee HT, Shen CC, Chung JG (2015) PEITC induces apoptosis of Human Brain Glioblastoma GBM8401 Cells through the extrinsic- and intrinsic -signaling pathways. Neurochem Int 81: 32-40.

Condon SM, Mitsuuchi Y, Deng Y, LaPorte MG, Rippin SR, Haimowitz T, Alexander MD, Kumar PT, Hendi MS, Lee YH, Benetatos CA, Yu G, Kapoor GS, Neiman E, Seipel ME, Burns JM, Graham MA, McKinlay MA Li X, Wang J, Shi Y, Feltham R, Bettjeman B, Cumming MH, Vince JE, Khan N, Silke J, Day CL, Chunduru SK (2014) birinapant, a smac-mimetic with improved tolerability for the treatment of solid tumors and hematological malignancies. J Med Chem 57: 3666-3677.

Day BW, Stringer BW, Al-Ejeh F, Ting MJ, Wilson J, Ensbey KS, Jamieson PR, Bruce ZC, Lim YC, Offenhauser C, Charmsaz S, Cooper LT, Ellacott JK, Harding A, Leveque L, Inglis P, Allan S, Walker DG, Lackmann M, Osborne G, Khanna KK, Reynolds BA, Lickliter JD, Boyd AW (2013) EphA3 maintains tumorigenicity and is a therapeutic target in glioblastoma multiforme. Cancer Cell 23: 238-248.

Eytan DF, Snow GE, Carlson SG, Schiltz S, Chen ZVan Waes C (2015) Combination effects of SMAC mimetic birinapant with TNFalpha, TRAIL, and docetaxel in preclinical models of HNSCC. Laryngoscope 125: E118-E124.

Filippini G, Falcone C, Boiardi A, Broggi G, Bruzzone MG, Caldiroli D, Farina R, Farinotti M, Fariselli L, Finocchiaro G, Giombini S, Pollo B, Savoiardo M, Solero CL, Valsecchi MG (2008) Prognostic factors for survival in 676 consecutive patients with newly diagnosed primary glioblastoma. Neuro Oncol 10: 79-87.
Fulda S (2014) Molecular pathways: targeting inhibitor of apoptosis proteins in cancer-from molecular mechanism to therapeutic application. Clin Cancer Res 20: 289-295.

Hanahan D, Weinberg RA (2000) The hallmarks of cancer. Cell 100: 57-70. Henry CM, Hollville E, Martin SJ (2013) Measuring apoptosis by microscopy and flow cytometry. Methods 61: 90-97.

Hetschko H, Voss V, Horn S, Seifert V, Prehn JH, Kogel D (2008) Pharmacological inhibition of Bcl-2 family members reactivates TRAILinduced apoptosis in malignant glioma. J Neurooncol 86: 265-272.

Jarzabek MA, Huszthy PC, Skaftnesmo KO, McCormack E, Dicker P, Prehn JH, Bjerkvig R, Byrne AT (2013) In vivo bioluminescence imaging validation of a human biopsy-derived orthotopic mouse model of glioblastoma multiforme. Mol Imaging 12: 161-172.

Jones TS, Holland EC (2012) Standard of care therapy for malignant glioma and its effect on tumor and stromal cells. Oncogene 31: 1995-2006.

Kitange GJ, Carlson BL, Schroeder MA, Grogan PT, Lamont JD, Decker PA, Wu W, James CD, Sarkaria JN (2009) Induction of MGMT expression is associated with temozolomide resistance in glioblastoma xenografts. Neuro Oncol 11: 281-291.

Krepler C, Chunduru SK, Halloran MB, He X, Xiao M, Vultur A, Villanueva J, Mitsuuchi Y, Neiman EM, Benetatos C, Nathanson KL, Amaravadi RK, Pehamberger H, McKinlay M, Herlyn M (2013) The novel SMAC mimetic birinapant exhibits potent activity against human melanoma cells. Clin Cancer Res 19: 1784-1794.

Lacasse EC, Mahoney DJ, Cheung HH, Plenchette S, Baird S, Korneluk RG (2008) IAP-targeted therapies for cancer. Oncogene 27: 6252-6275.

Li P, Nijhawan D, Budihardjo I, Srinivasula SM, Ahmad M, Alnemri ES, Wang X (1997) Cytochrome $\mathrm{c}$ and dATP-dependent formation of Apaf-1/caspase-9 complex initiates an apoptotic protease cascade. Cell 91: 479-489.

Lin Y, Devin A, Rodriguez Y, Liu ZG (1999) Cleavage of the death domain kinase RIP by caspase-8 prompts TNF-induced apoptosis. Genes Dev 13: 2514-2526.

Louis DN, Ohgaki H, Wiestler OD, Cavenee WK, Burger PC, Jouvet A, Scheithauer BW, Kleihues P (2007) The 2007 WHO classification of tumours of the central nervous system. Acta Neuropathol 114: 97-109.

Murphy AC, Weyhenmeyer B, Schmid J, Kilbride SM, Rehm M, Huber HJ, Senft C, Weissenberger J, Seifert V, Dunst M, Mittelbronn M, Kogel D, Prehn JH, Murphy BM (2013) Activation of executioner caspases is a predictor of progression-free survival in glioblastoma patients: a systems medicine approach. Cell Death Dis 4: e629.

Park S, Hatanpaa KJ, Xie Y, Mickey BE, Madden CJ, Raisanen JM, Ramnarain DB, Xiao G, Saha D, Boothman DA, Zhao D, Bachoo RM, Pieper RO, Habib AA (2009) The receptor interacting protein 1 inhibits p53 induction through NF-kappaB activation and confers a worse prognosis in glioblastoma Cancer Res 69:2809-2816.

Petersen SL, Peyton M, Minna JDWang X (2010) Overcoming cancer cell resistance to Smac mimetic induced apoptosis by modulating cIAP-2 expression. Proc Natl Acad Sci USA 107: 11936-11941.

Pollard SM, Yoshikawa K, Clarke ID, Danovi D, Stricker S, Russell R, Bayani J, Head R, Lee M, Bernstein M, Squire JA, Smith A, Dirks P (2009) Glioma stem cell lines expanded in adherent culture have tumor-specific phenotypes and are suitable for chemical and genetic screens. Cell Stem Cell 4: 568-580.

Riganti C, Salaroglio IC, Pinzon-Daza ML, Caldera V, Campia I, Kopecka J, Mellai M, Annovazzi L, Couraud PO, Bosia A, Ghigo D, Schiffer D (2014) Temozolomide down-regulates P-glycoprotein in human blood-brain barrier cells by disrupting Wnt3 signaling. Cell Mol Life Sci 71: 499-516.

Roos WP, Batista LF, Naumann SC, Wick W, Weller M, Menck CF, Kaina B (2007) Apoptosis in malignant glioma cells triggered by the temozolomideinduced DNA lesion O6-methylguanine. Oncogene 26: 186-197.

Roos WP, Kaina B (2013) DNA damage-induced cell death: from specific DNA lesions to the DNA damage response and apoptosis. Cancer Lett 332: $237-248$

Saggioro FP, Neder L, Stavale JN, Paixao-Becker AN, Malheiros SM, Soares FA, Pittella JE, Matias CC, Colli BO, Carlotti Jr CG, Franco M (2014) Fas, FasL, and cleaved caspases 8 and 3 in glioblastomas: a tissue microarraybased study. Pathol Res Pract 210: 267-273.

Straub CS (2011) Targeting IAPs as an approach to anti-cancer therapy. Curr Top Med Chem 11: 291-316.

Stupp R, Mason WP, van den Bent MJ, Weller M, Fisher B, Taphoorn MJ, Belanger K, Brandes AA, Marosi C, Bogdahn U, Curschmann J, Janzer RC, Ludwin SK, Gorlia T, Allgeier A, Lacombe D, Cairncross JG, Eisenhauer E, 
Mirimanoff RO (2005) Radiotherapy plus concomitant and adjuvant temozolomide for glioblastoma. N Engl J Med 352: 987-996.

Tenev T, Bianchi K, Darding M, Broemer M, Langlais C, Wallberg F, Zachariou A, Lopez J, MacFarlane M, Cain K, Meier P (2011) The Ripoptosome, a signaling platform that assembles in response to genotoxic stress and loss of IAPs. Mol Cell 43: 432-448.

Tivnan A, Zhao J, Johns TG, Day BW, Stringer BW, Boyd AW, Tiwari S, Giles KM, Teo C, McDonald KL (2014) The tumor suppressor microRNA, miR-124a, is regulated by epigenetic silencing and by the transcriptional factor, REST in glioblastoma. Tumour Biol 35: 1459-1465.

Varfolomeev E, Blankenship JW, Wayson SM, Fedorova AV, Kayagaki N, Garg P, Zobel K, Dynek JN, Elliott LO, Wallweber HJ, Flygare JA, Fairbrother WJ, Deshayes K, Dixit VM, Vucic D (2007) IAP antagonists induce autoubiquitination of c-IAPs, NF-kappaB activation, and TNFalpha-dependent apoptosis. Cell 131: 669-681.

Vellanki SH, Grabrucker A, Liebau S, Proepper C, Eramo A, Braun V, Boeckers T, Debatin KM, Fulda S (2009) Small-molecule XIAP inhibitors enhance gamma-irradiation-induced apoptosis in glioblastoma. Neoplasia 11: $743-752$.
Vince JE, Wong WW, Khan N, Feltham R, Chau D, Ahmed AU, Benetatos CA, Chunduru SK, Condon SM, McKinlay M, Brink R, Leverkus M, Tergaonkar V, Schneider P, Callus BA, Koentgen F, Vaux DL, Silke J (2007) IAP antagonists target cIAP1 to induce TNFalphadependent apoptosis. Cell 131: 682-693.

Wagner L, Marschall V, Karl S, Cristofanon S, Zobel K, Deshayes K, Vucic D, Debatin KM, Fulda S (2013) Smac mimetic sensitizes glioblastoma cells to Temozolomide-induced apoptosis in a RIP1- and NF-kappaB-dependent manner. Oncogene 32: 988-997.

Zou H, Henzel WJ, Liu X, Lutschg A, Wang X (1997) Apaf-1, a human protein homologous to C. elegans CED-4, participates in cytochrome c-dependent activation of caspase-3. Cell 90: 405-413.

This work is published under the standard license to publish agreement. After 12 months the work will become freely available and the license terms will switch to a Creative Commons AttributionNonCommercial-Share Alike 4.0 Unported License.

Supplementary Information accompanies this paper on British Journal of Cancer website (http://www.nature.com/bjc) 